\title{
Patient Satisfaction with Healthcare Service Delivery in an ART Treatment Centre in Nigeria
}

\author{
Osho Patrick Olanrewaju ${ }^{1, *}$, Adepoju Omoseni Oyindamola ${ }^{2}, J_{0 s e p h}$ Oluyemi ${ }^{3}$, \\ Gbenga-Fabusiwa Funmilayo $\mathrm{Joy}^{4}$, Oni Oluwatosin Idowu ${ }^{5}$, Ojo Oladotun Ayotunde ${ }^{6}$ \\ ${ }^{1}$ Department of Haematology \& Blood transfusion, Faculty of Basic Clinical Sciences, University of Medical Sciences, Ondo-City, Nigeria \\ ${ }^{2}$ Department of Business Administration, Federal University of Technology, Akure, Nigeria \\ ${ }^{3}$ Department of Sociology and Anthropology, Nelson Mandela University, Port-Elizabeth, South Africa \\ ${ }^{4}$ Department of Chemistry, University of Medical Sciences Teaching Hospital, Ondo, Nigeria \\ ${ }^{5}$ Department of Haematology/Virology, University of Medical Sciences Teaching Hospital, Akure, Nigeria \\ ${ }^{6}$ Department of Physics, Biophysics and Medical Physics Unit, Osun State University, Osogbo, Nigeria
}

\section{Email address:}

droshopo@gmail.com (Osho P. O.), adepojuomoseni@gmail.com (Adepoju O. O.), josepholuyemil@gmail.com (Joseph O.), fjgbenga@unimed.edu.ng (Gbenga-Fabusiwa F. J.), godsprince805@gmail.com (Oni O. I.), oladotun.ojo@uniosun.edu.ng (Ojo O. A.)

${ }^{*}$ Corresponding author

\section{To cite this article:}

Osho Patrick Olanrewaju, Adepoju Omoseni Oyindamola, Joseph Oluyemi, Gbenga-Fabusiwa Funmilayo Joy, Oni Oluwatosin Idowu, Ojo Oladotun Ayotunde. Patients' Satisfaction with Healthcare Service Delivery in an ART Treatment Centre in Nigeria. International Journal of HIV/AIDS Prevention, Education and Behavioural Science. Vol. 6, No. 2, 2020, pp. 44-52. doi: 10.11648/j.ijhpebs.20200602.13

Received: May 24, 2020; Accepted: July 13, 2020; Published: September 16, 2020

\begin{abstract}
Optimal Service delivery is imperative for a favorable patients' care outcome. PLWHV have social and welfare needs asides their health need. Healthcare service delivery is key to meeting these needs. This study assessed the level of satisfaction of PLWHV with the Healthcare service they are being provided with at a tertiary hospital in Nigeria. The crosssectional study involved the use of structured questionnaire containing closed and open ended questions as an instrument for data collection, having employed the non-probability convenience sampling method to select respondents for the study. A total of 143 respondents participated in the study out of the 150 questionnaires that was distributed representing $95.3 \%$ response rate. Primary data were analyzed using Frequency, means score rating and Regression analysis after a Cronbach Alpha greater than 0.70 . The study showed that services provided have significant effect on the level of patients satisfaction at $(\mathrm{R}=0.574$, $\mathrm{R}^{2}=0.305$ and sig=0.00; $\left.\mathrm{P}<0.05\right)$. The study concludes that the four types of services provided to HIV/ AIDS patients have more effect on their level of satisfaction than other types of services. It recommends that services provided to HIV/ AIDS patients should exhibits the following twelve (12) characteristics; qualitative, prompt, unambiguous, focused, friendly, nonjudgmental, elaborate, preventive, meticulous, futuristic, healthy and of good memory.
\end{abstract}

Keywords: Patients Satisfaction, HIV/ AIDS, Service Delivery

\section{Introduction}

Available data from Nigeria HIV/ AIDS Indicator and Impact Survey (NAIIS), stipulated that there are 1.9 Million people living with HIV/ AIDS in Nigeria. This makes Nigeria the fourth country in the world with high number of PLWHA after South Africa, Mozambique and India [2]. However, iproving healthcare service delivery is essential towards achieving the United Nations Sustainable Development Goals three (3), which as part of its goal aims to end the
AIDS epidemic by year 2030 [56]. This place a global demand on the need for countries especially developing countries to strengthen their healthcare system in order to tackle high mortality rates that can also be triggered by the burden of HIV/AIDS [44].

It is therefore worthy to note that Patients' satisfaction is a key measure of quality service delivery and positive feedback from the service utilizers [10]. This leads to the goodwill of the service providers, especially for life threatening disease like HIV/ AIDS. Client satisfaction often determines whether 
a client seeks medical advice and care and adheres to a prescribed treatment schedule [21]. Today, patients are aware of their rights in terms of healthcare services and the quality of healthcare services being delivered to them [10].

PLWHA in Nigeria are faced with various challenges in accessing health care services, shortage of manpower, congested health care facilities, knowledge gap among health care providers, side effect of the drugs, high cost of treatment and fluctuating funding of the different programs for PLWHA by the Federal government of Nigeria $[42,45,38]$.

They are also faced with difficulties of low socioeconomic status, long waiting times, inadequate knowledge of the disease, user fees, stigma and discrimination, interference with ART therapy as well as ethical contentions due to high cost of antiretroviral drugs $[42,15]$.

All these and many motivated the study hence the need to assess the quality of healthcare service rendered to PLWHA as it will provide government, health care management bodies, policy makers in health matters information and international health bodies, information about how HIV/ AIDS treatment program in the state have fared.

\section{Statement of the Problem}

Nigeria has the fourth highest burden of HIV/AIDS globally. [17]. Despite these high figures of PLWHA, there are challenges in assessing health care services. These challenges can be categorized into three; patients related, health systems related and community related challenges [45, 39]. The health related systems challenges includes, fluctuating funding of programmes and medicines for PLWHA, legal reforms to facilitated mass production of generic products for the patients, shortage of manpower especially due to high labour turnover, highly congested and poorly coordinated health care facilities, sides effect of the drugs [16, 45, 42]. Patients related challenges however include long distance to the health care facilities, poor socioeconomic status, long waiting times, and inadequate knowledge of HIV [15]. Furthermore, the community related challenges includes stigma and discrimination against PLWHA, and interference by religious leaders and faith preachers, [42] Dissatisfaction with healthcare services being rendered can have serious consequences among which is treatment default by patient, loss to follow-up and reduced service utilization by the dissatisfied patient who may discourage others from using the facility. [3].

\section{Methodology}

The study was conducted at the University of Medical Sciences Teaching Hospital Complex (UNIMEDTH), Ondo State, Southwest Nigeria. A total of 143 respondents selected through a two-staged sampling method were recruited in the study. Using simple random sampling technique, the two ART clinics in the teaching hospital, with each one in Akure city and Ondo town centers was chosen, and a purposive sampling method was used to select respondents for the study.
Information was retrieved through administration of structured questionnaire comprising of closed questions. The research instrument was divided into five parts, part one addressed the social demographic information of the respondents, part two contained questions on patient satisfaction with the healthcare service rendered in general using SERVQUAL framework consisting of five dimensions; Tangibles, Reliability, Responsiveness, Assurance, and Empathy. Part three assessed the level of service delivery provided by the hospital using 22 indicators that tests patient's perception about services provided while part four assessed the patient's satisfaction with the specific healthcare service rendered viz a viz the four types of services provided by the health facility and part five assessed the experience of the patients during their medical visits. A five point Likert scale was used to measure the participant's rating of the nineteen (19) indicators for the five (5) dimensions. The Likert scales ranges from $5=$ strongly agree, 4=Agree, $3=$ Undecided, $2=$ Disagree and $1=$ Strongly Disagree. The data collected were analyzed using Statistical Package for social science (SPSS version 25.0), using research tools of frequency, percentage, Mean Score rating and Regression analysis.

Ethical approval was obtained from the State Ministry of Health before the research was conducted while informed consent was also obtained from respondents before the study was conducted. Also, confidentiality was ensured as there was no name requested from the respondents or any other personal information unrelated to the study objectives.

\section{Results}

The socio demographic characteristics of participants were highlighted in Table 1 below.

The table revealed that $26.6 \%$ of the respondents were male, giving a $\mathrm{M}$ : $\mathrm{F}$ ratio of 0.36 . Majority $(53.15 \%)$ of the Participants were aged $30-39$, while $1.39 \%$, were below 20 years, $13.28 \%$ were $20-29$ years and $32.17 \%$ of the respondents were above 40 years. $65 \%$ of the respondents were married, $13.3 \%$ single, $8.4 \%$ divorced and $13.3 \%$ widowed. A review of the highest level of educational attainment by respondents showed that $8.4 \%$ of the respondents had no formal education, $21 \%$ didn't go beyond primary school, $54.5 \%$ stopped their education at secondary schools, $2.8 \%$ are still in tertiary institutions, $11.2 \%$ are graduates and $2.1 \%$ are post graduate students. Likewise, looking at the economic status of the respondents, $36.4 \%$ were skilled workers, $26.6 \%$ were semi - skilled workers, $23.8 \%$ were unskilled workers and $13.3 \%$ were unemployed. This occupational statistics revealed that $63.7 \%$ of the respondents have staggering economic conditions. Also, the table revealed that $55.94 \%$ of the respondents were diagnosed in the last five (5) years, which shows that many of the patients were recently infected and will have a fresh perspective on the service delivery given in the health care center. 
Table 1. Socio-Demographic Characteristics of Respondents.

\begin{tabular}{|c|c|}
\hline Characteristics & Frequency (\%) \\
\hline \multicolumn{2}{|l|}{ Gender } \\
\hline Male & $38(26.6)$ \\
\hline Female & $105(73.4)$ \\
\hline Total & $143(100.0)$ \\
\hline \multicolumn{2}{|l|}{ Age } \\
\hline$\leq 20$ years & $2(1.4)$ \\
\hline$\leq 29$ years & $19(13.28)$ \\
\hline$\leq 39$ years & $76(53.15)$ \\
\hline$\geq 40$ years & $46(32.17)$ \\
\hline Total & $143(100)$ \\
\hline \multicolumn{2}{|l|}{ Marital Status } \\
\hline Married & $93(65.0)$ \\
\hline Single & $19(13.3)$ \\
\hline Divorced & $12(8.4)$ \\
\hline Widowed & $19(13.3)$ \\
\hline Total & $143(100.0)$ \\
\hline \multicolumn{2}{|l|}{ Educational Status } \\
\hline None & $12(8.4)$ \\
\hline Primary & $30(21.0)$ \\
\hline Secondary & $78(54.5)$ \\
\hline Tertiary & $4(2.8)$ \\
\hline Graduate & $16(11.2)$ \\
\hline Post-Graduate & $3(2.1)$ \\
\hline Total & $143(100.0)$ \\
\hline \multicolumn{2}{|l|}{ Occupational Status } \\
\hline Skilled worker & $52(36.4)$ \\
\hline Semi - Skilled worker & $38(26.6)$ \\
\hline Unskilled worker & $34(23.8)$ \\
\hline Unemployed & $19(13.3)$ \\
\hline Total & $143(100.0)$ \\
\hline \multicolumn{2}{|l|}{ Years of Diagnosis } \\
\hline $0-5$ & $80(55.94)$ \\
\hline $6-10$ & $53(37.06)$ \\
\hline $11-15$ & $9(6.29)$ \\
\hline $16-20$ & $1(0.7)$. \\
\hline Total & $143(100.0)$ \\
\hline
\end{tabular}

Researcher's Survey (2019).

In order to assess the level of HIV treatment service delivery at UNIMEDTHC, patients perception of the services provided was sought, using twenty - two (22) indicators as identified from various literature reviews (Figure 1). In this survey, patient were asked to rank the services provided to them in ascending order of satisfaction with the service. The service most satisfying is ranked as first while the least satisfying is ranked twentysecondth. The first five indicators ranked by the patients includes 'the health facilities tells exactly when services will be performed' (with a mean of 4.63 and standard deviation of 0.64 ); 'accurate keeping of records' (with a mean of 4.63 and standard deviation of 0.69 ); 'health workers are polite in providing services' (with a mean of 4.61 and standard deviation of 0.54 ); 'patients feel safe during communication and transactions with health workers' (with a mean of 4.61 and standard deviation of $0.62)$; 'health workers dresses well and appear neat, showing their level of consciousness in providing services' (with a mean of 4.60 and standard deviation of 0.77 ).

Also, the respondents ranked the following five services least and they include 'the sympathetic and reassuring nature of the health workers to the patients' (with a mean of 4.19 and standard deviation of 1.14); 'prompt services from the health workers' (with a mean of 4.38 and standard deviation of 0.94 ); 'high correlation between the hospital environment and the services they provides' (with a mean of 4.45 and standard deviation of 0.76 ); 'health workers are not too busy to responds to patients request promptly' (with a mean of 4.48 and standard deviation of 0.76 ) and 'the health care is dependable' (with a mean of 4.49 and standard deviation of 0.79 ).

\section{Participant's Perception of Healthcare Service Delivery}

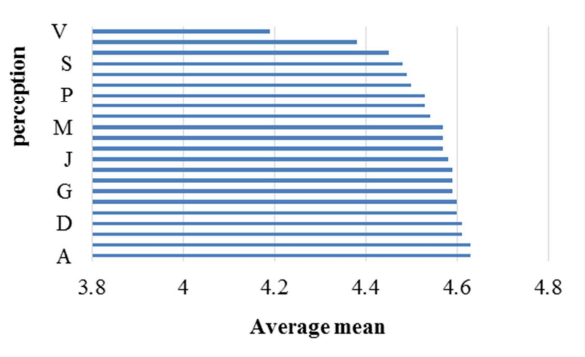

Figure 1. Participant'S perception of the healthcare service.

Table 2. KEY

\begin{tabular}{ll}
\hline A & The health facilities tells exactly when services will be performed \\
B & It keeps its records accurately \\
C & Its health workers are polite \\
D & You can feel safe in your communication and transactions with health \\
E & workers \\
F & Their health workers are well dressed and appear neat. \\
G & Health care workers give patients personal attention \\
H & This health facility gives patients individual attention. \\
I & This health facility has your best interests at heart. \\
J & This health facility has operating hours convenient to their entire patients. \\
K & You can trust the health workers of this health facility. \\
L & When it promises to do something by a certain time, it does so. \\
M & Health workers are always willing to help patients \\
N & Health care workers know what your needs are \\
O & Its employees get adequate support to do their jobs well. \\
P & The health facility has up - to - date equipment \\
Q & Its physical facilities are virtually appealing \\
R & The health facility is dependable \\
S & Health workers are not too busy to respond to patients requests promptly \\
T & The appearance of its physical facilities is in keeping with the type of \\
U & Services provided. \\
V & wou receive prompt service from their health workers. \\
\hline &
\end{tabular}

Researcher's survey (2019).

Depicted in Table 3 is respondents' level of satisfaction with the services provided to them using the SERQUAL five (5) dimensions of Responsiveness, Tangible, Reliability, Assurance and Empathy. They were satisfied with the Responsiveness of the system hence ranked it high with a mean of 4.53 and standard deviation of 0.47 as health workers willingly provides prompt service in terms of administering retroviral drugs and correct interpretation of laboratory results. The respondents ranked Reliability next to Responsiveness as the next dimension they were satisfied with, with a mean of 4.51 and standard deviation of 0.47 
revealing the dependability of the patients on the health workers expertise and accurate ability to give proper description and dosage of drug since the health workers are supervised and monitored. The respondents ranked Tangible dimension next to Reliability with a mean of 4.49 and standard deviation of 0.57 , indicating that the patients believe that both the health care facility environment and the physical appearance of the health workers are appealing and hygienic. The fourth ranked dimension is the Assurance dimension with a mean of 4.42 and standard deviation of 0.49 . This revealed the moderate level of courteous behavior of the health workers towards the patients. The last dimension according to the respondents is Empathy dimension, with a mean of 4.36 and standard deviation of 0.58 . This shows the moderate level of compassion showed to the patients while receiving treatment for HIV/ AIDS.

Table 3. Assessing Patients Satisfaction with the Quality of Service Delivery.

\begin{tabular}{|c|c|c|c|}
\hline Dimensions/ indicators & Mean & Standard Deviation (SD) & Rank \\
\hline \multicolumn{4}{|l|}{ Responsiveness } \\
\hline Retroviral drugs are always available and administered as required & 4.56 & 0.51 & \\
\hline The service equipment are always available and functional & 4.54 & 0.54 & \\
\hline Health workers correctly interpret laboratory results to the patients & 4.50 & 0.58 & \\
\hline Responsiveness total Mean & 4.53 & 0.47 & $1^{\mathrm{st}}$ \\
\hline \multicolumn{4}{|l|}{ Reliability } \\
\hline Health workers give proper description of how the drugs are to be used & 4.59 & 0.53 & \\
\hline There is regular drug supply at the health center & 4.57 & 0.49 & \\
\hline Health workers are adequately supervised to ensure proper care process & 4.37 & 0.65 & \\
\hline Reliability total mean & 4.51 & 0.47 & $2^{\text {nd }}$ \\
\hline \multicolumn{4}{|l|}{ Tangibles } \\
\hline The staff at the health facilities dresses neatly and professionally for the services delivered. & 4.49 & 0.65 & \\
\hline The environment of the health facilities is hygienic and always clean. & 4.49 & 0.82 & \\
\hline $\begin{array}{l}\text { The health facilities ensures that the required equipment is available and up - to - date (modern) to } \\
\text { attend to patient's needs. }\end{array}$ & 4.48 & 0.54 & \\
\hline Tangibles Total mean & 4.49 & 0.57 & $3^{\text {rd }}$ \\
\hline \multicolumn{4}{|l|}{ Assurance } \\
\hline Health workers provide explanation to the patients when required & 4.52 & 0.54 & \\
\hline Heath workers correctly diagnose disease & 4.47 & 0.54 & \\
\hline Health workers are courteous and respectful to patient & 4.45 & 0.67 & \\
\hline Heath workers observe privacy and confidentiality with patents information & 4.41 & 0.82 & \\
\hline Heath workers correctly interpret laboratory results to the patients & 4.38 & 0.79 & \\
\hline Health workers are fair in providing needed services & 4.32 & 0.79 & \\
\hline Assurance Total Mean & 4.42 & 0.49 & $4^{\text {th }}$ \\
\hline \multicolumn{4}{|l|}{ Empathy } \\
\hline Health workers show adequate care when attending to patients & 4.41 & 0.71 & \\
\hline Health workers are attentive and always give patients enough time to discuss their medical problems. & 4.40 & 0.66 & \\
\hline Health workers are understanding and sympathetic & 4.33 & 0.77 & \\
\hline Health workers provide personal care and mental support & 4.29 & 0.76 & \\
\hline Empathy total mean & 4.36 & 0.58 & $5^{\text {th }}$ \\
\hline \multicolumn{4}{|l|}{ Overall response } \\
\hline overall feeling about the services rendered at the hospital & 4.46 & 0.52 & \\
\hline
\end{tabular}

Researcher's survey (2019).

The effect of service delivery on patient satisfaction was tested using regression analysis, the result of which is shown in Table 4. It revealed the statistical significance of the regression model, where the significance difference of 0.000 $(\mathrm{P}<0.05)$ indicates that the regression model statistically and significantly predicts the outcome variable. Hence, the null hypothesis 1 was rejected and its alternate hypothesis accepted that HIV / AIDS service delivery have significant effect on Patient satisfaction. The types of services rendered at the facility ART clinic include Counselling, Prevention, ARV therapy and Follow-up (figure 2).

Table 4. Model Summary and ANOVA table for the effect of Service Delivery on Patient Satisfaction.

\begin{tabular}{|c|c|c|c|c|c|c|}
\hline Model & $\mathbf{R}$ & \multicolumn{2}{|l|}{ R Square } & Adjusted R Square & \multicolumn{2}{|c|}{ Std. Error of the Estimate } \\
\hline 1 & $.574^{\mathrm{a}}$ & .330 & & .305 & \multicolumn{2}{|c|}{.36429} \\
\hline \multicolumn{7}{|c|}{ ANOVA $^{a}$} \\
\hline \multicolumn{2}{|l|}{ Model } & Sum of Squares & df & Mean Square & $\mathbf{F}$ & Sig. \\
\hline \multirow{3}{*}{1} & Regression & 8.940 & 5 & 1.788 & 13.474 & $.000^{\mathrm{b}}$ \\
\hline & Residual & 18.181 & 137 & .133 & & \\
\hline & Total & 27.121 & 142 & & & \\
\hline
\end{tabular}

a. Dependent Variable: Patients Satisfaction.

b. Predictors: (Constant), Service Delivery. 


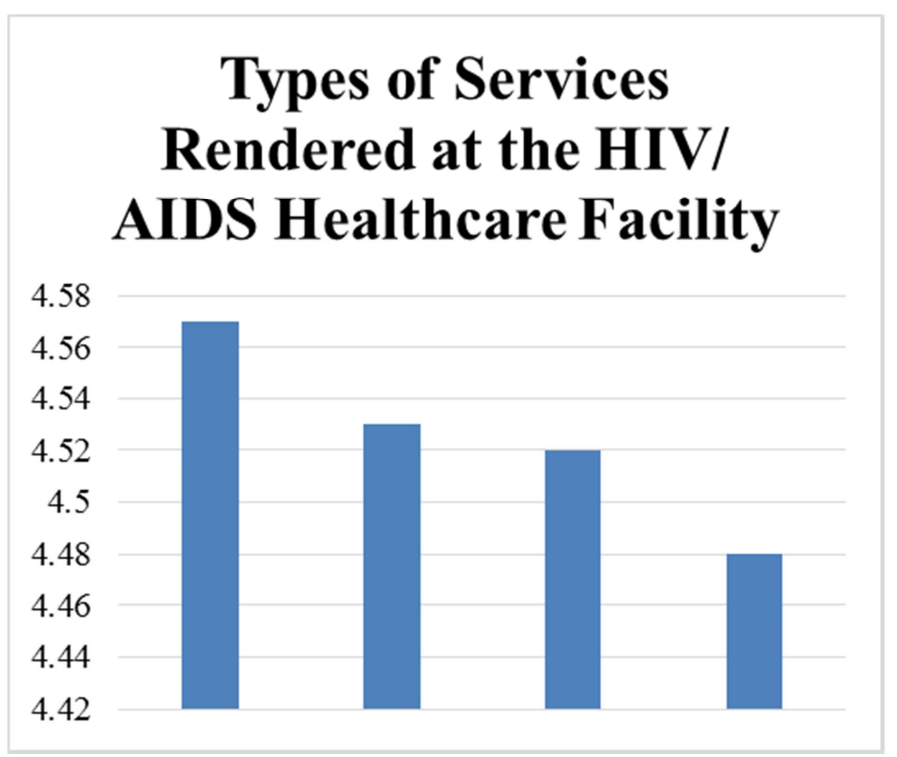

Figure 2. Health care service rendered at the UNIMEDTHC ART clinic.

The patients relate their experience during medical visits to the clinics (Table 5). Theyopined that the services being provided to them exhibits the following characteristics of being qualitative, prompt, unambiguous, focused, friendly, non judgmental, elaborate, preventive, meticulous, futuristic, healthy and of good memory.

Table 5. Patients Experience during HIV Medical Visit.

\begin{tabular}{|c|c|c|c|}
\hline Experiences & Mean & Standard Deviation & Ranks \\
\hline If I had a complaint about my medical care, my providers would ignore it & 2.77 & 0.62 & $1^{\mathrm{st}}$ \\
\hline It was hard for me to get my HIV medication prescriptions filled when I needed them & 2.65 & 0.72 & $2^{\text {nd }}$ \\
\hline When I saw my service providers, my visits got interrupted (by phone calls or other patients) & 2.57 & 0.80 & $3^{\text {rd }}$ \\
\hline When I asked my providers about my HIV care, it was hard to understand their answers. & 2.42 & 0.88 & $4^{\text {th }}$ \\
\hline I found my providers to be accepting and non - judgmental of my life and health care choices & 1.85 & 0.97 & $5^{\text {th }}$ \\
\hline My providers explained the side effects of my HIV medications in a way I could understand. & 1.15 & 0.51 & $6^{\text {th }}$ \\
\hline My providers explained to me how to avoid getting sick & 1.13 & 0.48 & $7^{\text {th }}$ \\
\hline My providers made sure that I understood what my lab test results (such as CD4 and viral load) meant for my health & 1.13 & 0.49 & $8^{\text {th }}$ \\
\hline When I go for medical care, they were careful on checking everything when treating and examining me. & 1.09 & 0.43 & $9^{\text {th }}$ \\
\hline My health providers explained to me what kinds of medical tests I should be getting and how often I should get them. & 1.08 & 0.37 & $10^{\text {th }}$ \\
\hline My health providers suggested ways to help me remember to take my HIV medications & 1.08 & 0.36 & $11^{\text {th }}$ \\
\hline $\begin{array}{l}\text { My health providers talked to me about how to avoid passing HIV to other people and how to protect myself from } \\
\text { getting infected again with HIV }\end{array}$ & 1.04 & 0.29 & $12^{\text {th }}$ \\
\hline
\end{tabular}

The Co - efficient Model of Parameters of Table 6 shows the level of effect the four types of services have on patient's satisfaction. Table 6 revealed that only two types of services have statistically significant effect on patient's satisfaction. These are counseling services $(\operatorname{sig}=0.018, \mathrm{P}<0.05)$ and antiretroviral therapy service $(\mathrm{sig}=0.000, \mathrm{P}<0.05)$. However, standardized beta values showed that antiretroviral therapy services (at a beta value of 0.369) have more effect on patient satisfaction than counseling services (at beta value of 0.206). This indicates how the patients wants the disease eradicated from their body system as soon as possible.

Table 6. Model Summary and co-efficient of Model Parameters for the effect of the four types of services on Patient Satisfaction.

\begin{tabular}{|c|c|c|c|c|c|c|c|}
\hline \multicolumn{8}{|c|}{ Model Summary } \\
\hline \multicolumn{2}{|c|}{$\begin{array}{l}\text { Model } \\
1\end{array}$} & $\begin{array}{l}\mathrm{R}^{2} \\
.368\end{array}$ & \multicolumn{2}{|c|}{$\begin{array}{l}\text { Adjusted } \mathrm{R}^{2} \\
.350\end{array}$} & \multicolumn{3}{|c|}{$\begin{array}{l}\text { Std. Error of the Estimate } \\
1.75221\end{array}$} \\
\hline \multicolumn{8}{|c|}{ Coefficients $^{\mathrm{a}}$} \\
\hline \multirow{2}{*}{\multicolumn{2}{|c|}{ Model }} & \multicolumn{2}{|c|}{ Unstandardized Coefficients } & \multicolumn{2}{|c|}{ Standardized Coefficients } & \multirow{2}{*}{ t } & \multirow{2}{*}{ Sig. } \\
\hline & & $\mathbf{B}$ & Std. Error & Beta & & & \\
\hline \multirow{5}{*}{1} & (Constant) & 9.376 & 1.499 & & & 6.255 & .000 \\
\hline & Counseling services & .693 & .290 & .206 & & 2.388 & .018 \\
\hline & Antiretroviral therapy services & 1.601 & .427 & .369 & & 3.752 & .000 \\
\hline & Medical checkup services & .179 & .246 & .059 & & .728 & .468 \\
\hline & Prevention services & .382 & .299 & .102 & & 1.275 & .204 \\
\hline
\end{tabular}

a. Dependent Variable: Patients Satisfactions. 
Test of Hypotheses:

HO1: HIV/ AIDS service delivery does not have significant effect on the level of HIV/ AIDS patient's satisfactions.

HO2: Four types of services provided to HIV/ AIDS patients does not significant effect on the level of HIV/ AIDS patient's satisfaction.

Reliability test was conducted on the data collected and generated the following Cronbach's Alpha value; patients satisfaction (Cronbach Alpha value of 0.926), services provided (Cronbach's Alpha value of 0.921) and the four types of services provided (Cronbach Alpha value of 0.743 ). These values are higher than the 0.70 recommended in Nunnally's (1978) guideline.

\section{Discussion}

Being confirmed as HIV positive is mentally exerting as many people reacts negatively to the news, with feelings such as fear, anger, and a sense of being overwhelmed. Meeting the health, social and welfare needs of these group of individual goes a long way in allaying fears, ensuring a prolonged and quality living, enhance their willingness to access care as well as limit transmission of infection as the infected is better informed about the condition.

Healthcare Services rendered in the hospital, centred around meeting the health needs of these patients, is expected to generate a response from the user (the patient). The response could either be satisfactory or otherwise. Using any of these service, the user has an expectation which if met by the facility (hospital) rendering the service, the outcome is patient satisfaction, dissatisfaction if the performance falls below the user's expectation. Patient's satisfaction which has been defined as an evaluation that reflects the perceived differences between expectations of the patient to what is actually received during the process of care, is an important tool in measuring quality in healthcare delivery. It is on this background that the study was conducted to access the quality of ARV treatment care UNIMEDTHC is rendering to PLWHV in the state.

The study a predominant adult population of care recipients as more than $80 \%$ of the respondents are above 30 years old. The mental maturity of the patient, most likely the function of their age, reflected in their understanding of the disease condition, accessing care and making a good use of available service.

Patient's perception of services rendered to them by the facility revealed five (5) indicators which they were most satisfied with, which were carrying patient along in their management by informing them about the care being rendered per time and when it will be rendered, their medical records being properly kept and accounted for, politeness of healthcare worker, ease of communication with healthcare worker with assurance of confidentiality and the neat and well groomed appearance of the healthcare worker.

These first five ranked services perception revealed that
UNIMEDTH is well prepared to provider qualitative service to HIV/AIDS patients. These further shows the high level of seriousness the teaching hospital management and staff have regarding the treatment of HIV/ AIDS. This is in conformity with the Family Health International (2018) manual of preparedness for HIV/ AIDS services provision.

The health facilities telling exactly when services will be performed is an indication of its reliability, this reliability improves the patient's confidence in the system. The patients further opined that the facility keeps its records accurately, knowing when individual patients need a particular service. Likewise, record retrieval in terms of case folders is the first activity in seeking medical attention when a patient arrives in the hospital. When such records are misplaced or difficulty in retrieving is experienced, the patient can be discouraged from accessing care in that facility especially if it is a recurring occurrence. This makes the patient dissatisfied with the service provided. In institutions where separate record office is not maintained for reactive patients, the tortuous process of case folder retrieval is an avenue for exposing the patient to be stigmatized as questionings, queries, verbal interaction may ensue between patient and health record officer in the hearing of other patients that may end up in stigmatizing the seropositive patient. Its health workers politeness may contribute to the overall satisfaction recorded as studies have shown that Polite and courteous behavior of the healthcare worker is necessary in hospital services as it ensures a hospitable environ for the already distressed and most likely anxious patient patients say they can feel safe in your communication and transactions with health workers which is particularly an important virtue Due to the sensitive nature of HIV diagnosis and the stigmatization and discrimination patients are prone to which is still a major challenge in the care and treatment of the HIV positive, the ones that summon courage to access care need to have confidence in the service provider, knowing that information about him/her will not go past the four walls of the consulting room. There have been instances when stigmatization and discrimination against sreropositive patients occurred within the hospital environment, among healthcare workers who are treatment providers.

Furthermore, patients noted that the health workers are well dressed and appear neat. This will contribute positively to overall satisfaction with care as studies have shown that physical appearance influenced patient opinion of medical care [14].

Likewise, Health care workers give patients personal attention knowing that some of the basic rights of a patient are Privacy and confidentiality. When these are guaranteed, it serves towards a trustful, frank and open relationship with the doctor, thus improving patient care [45]. When patients are satisfied with the attitude of providers when these services are being delivered, treatment outcome and prognosis is expected to be positively influenced [1].

Least satisfying indicators were the sympathetic and reassuring nature of the health workers to the patients, 
prompt services from the health workers, hospital environment not befitting for ART service provision, health workers willingness and promptness in answering questions and a dependable care.

These least five ranking revealed the internal mechanism of operation of the hospitals as regards providing services for HIV/ AIDS patients, especially the modus operandi of the health workers. It further revealed that though the health workers are prepared, they are somewhat complacent and unintentionally demonstrates carefree attitudes because of the status of the patients. Due to the number of patients per clinic visit, waiting might become inevitable while awaiting being seen by a doctor. Other points where waiting is probable is at medical records when retrieving case file or booking appointment, at the pharmacy where drugs will be picked up and at the laboratory. This may result to dissatisfaction in the patient. This waiting time is an important area to address for enhancing overall satisfaction ratings. The period of wait can be shortened by instituting measures such as measures like strict adherence of queue discipline, no queue jumping and First in First out (FIFO) policy and the time spent waiting can be made less boring by provision of magazines, television and other means of entertainment in the waiting room [14]. This can serve the dual function of keeping patient entertained while they wait as well as making the facility befitting for ART care service delivery.

Moreover, assessing the gap between the first five ranked indicators of service delivery perception and the last five indicators revealed that there is a psychological gap between level of readiness and level of administering treatment to HIV/AIDS patients. This shows that body language of health workers are seemingly reverse to the operations they performed.

Examining the Quality of Service Delivery and the Level of Patients Satisfaction with it, 5 indicators/ dimensions were used among which Responsiveness of the service delivered was ranked first, indicating that the health workers willingly provides prompt service in terms of administering retroviral drugs and correct interpretation of laboratory results. The next quality of the service rendered by the facility that the patients were satisfied with was Reliability dimension revealing the dependability of the patients on the health workers expertise and accurate ability to give proper description and dosage of drug since the health workers are supervised and monitored. The respondents ranked Tangible dimension as third indicating that the patients believe that both the health care facility environment and the physical appearance of the health workers are appealing and hygienic. The fourth ranked dimension is the Assurance dimension revealing the moderate level of courteous behavior of the health workers towards the patients. The last dimension according to the respondents is Empathy dimension which shows the moderate level of compassion shown to the patients while receiving treatment for HIV/ AIDS. The overall level of satisfaction in the patient the grand mean is 4.46 and standard deviation of 0.52 , which revealed that the patients are highly satisfied with the general services provided to them at the University of Medical Sciences Teaching Hospital Complex. Thus, this is conformity with the research of Tran, Dang, Thu Vu, Tran, Latkin, Ho and Ho [46].

The four (4) types of ART related service delivered in the facility were examined to find out which had an effect on patient satisfaction. Two (2) had statistically significant effect on patient satisfaction, these are counseling services ( $\mathrm{sig}=0.018, \quad \mathrm{P}<0.05)$ and antiretroviral therapy service ( sig=0.000, $\mathrm{P}<0.05$ ). However, standardized beta values showed that antiretroviral therapy services (at a beta value of 0.369) have more effect on patient satisfaction than counseling services (at beta value of 0.206). This indicates how the patients want the disease eradicated from their body system as soon as possible.

\section{Conclusion and Recommendations}

Result from the study showed that respondents in the studied population are satisfied with the level of services provided to them gauging by their high level of perception of service delivery at an average mean of 4.54 and high level of satisfaction with services rendered at an average mean of 4.46. The result also shows that HIV/AIDS health care services have significant effect on patient's satisfaction at an $\mathrm{R}$ value of 0.574 . Furthermore, from the difference in the correlation value of $\mathrm{R}$ (s) of the two regression model, between the general services provided $(\mathrm{R}=0.574)$ and the four types of services provided $(\mathrm{R}=0.607)$ to $\mathrm{HIV} / \mathrm{AIDS}$ patients and their level of satisfaction, indicates that the four major types (counseling services, ART services, Medical checkup services and Prevention of Mother-to-child transmission services) of services should be prioritized before other types of services. This will boost the healthy life of the patients as a result of their satisfaction level.

The study recommends that, services provided for HIV patients should be balance and prioritized in line with in the following order; ART services, counseling services, Prevention services and Medical checkup services. The study also recommends that health care providers in the studied population should improve in their attitudes towards patients by empathizing and discharging their services in line with international best practices. Lastly, health workers should demonstrate the following characteristics when providing services to HIV/ AIDS patients; qualitative, prompt, unambiguous, focused, friendly, non - judgmental, elaborate, preventive, meticulous, futuristic, healthy and of good memory.

\section{References}

[1] Acharya, J. P., and Acharya, I., (2003). A study on compliance and behavioural responses of patients in an outpatient clinic. Indian J Community Med. 2003; 28: 19-25.

[2] Adebowale, N., (2019). Nigeria improves on HIV ranking; Now fourth worst Hit Country. Premium Time. Retrieved from https://allafrica.com/stories/201903150021.html Accessed 15/03/2019. 
[3] Andaleeb, S., Siddiqui, N., \& Khandakar, S. (2007). Patient satisfaction with health services in Bangladesh. Health Policy and Planning, 22, 263-273.

[4] Anderson, E. W. (1996). Customer satisfaction and Price Tolerance.

[5] Bach Xuan Tran and Nhung Phuong Thi Nguyen (2012): Patient satisfaction with HIV/ AIDS care and treatment in the Decentralization of services Delivery in Vietnam; PLoS One, Open Access Journal 7 (10): e46680.

[6] Boshoff, C. and Gray, B. (2004). The relationship between service quality, customer satisfaction and buying intentions in the private hospital industry. South Africa. Bus. Management, 35 (4): $29,33$.

[7] Community intervention. BMC Int Health Hum Rights. 2012; 12: 6. Community: characteristics, correlation with HIV knowledge and other factors, and implications for Ferri, M., Brooks, D. and Goldstein, R. S. (1998). Compliance with treatment-an ongoing concern. Phy Canada, 50 (4): 287-290.

[8] Friebel, R. (2017, August 24). Measuring quality of health care in the NHS: Giving a voice to the patients. Retrieved from The health foundation: http://www.health.org.uk/blog/measuring-quality-health-carenhs-giving-voice-patients Gou 2008, UNGASS country progress report Uganda. January 2006 to december 2007.

[9] Grol, R, and Wensing, M. (2000). Patients evaluate general/family practice. The EUROPEP instrument. Equip, WONCA Region Europe.

[10] Gupta, K. S., and Rokade, V., (2016). Importance of Quality in Health care sector: A review. Journal of Health Management, 18 (1). https://doi.org/10.1177/0972063415625527.

[11] Hall, J. and Dornan, M. (1990). Patient Sociodemographic Characteristics as Predictors of Satisfaction with Medical Care: A Meta-Analysis. So Sci; 30 (1): 21-26.

[12] Hair, J. F., Black, W., Babin, B. J., and Anderson, R. E., (2010). Multivariate Data analysis. Seventh Edition. Pearson New international edition. ISBN 10: $1-292-02190-8$.

[13] Hardie, N., \& Walsh, P. (1994). Towards a better understanding of quality. Int. J. Qual. Reliab. Manage., 11 (4), $53-64$.

[14] Henri, G. C., and Jerald, A. S., (1989). Attitudes of patients and physicians regarding physician dress and demeanour in the emergency department. Annals of Emergency Medicine. 1989.18 (2): 145-151.

[15] Hodgson, I., Plummer, M. L., Konopka, S. N., Colvin, C. J., \& Jonas, E. (2014). A Systematic Review of Individual and Contextual Faactors Affecting ART Initiation, Adherence, and Retention for HIV-Infected Pregnant and Postpartum Women.

[16] Hoen, E. T., Calmy, A., \& Moon, s. (2011). Driving a decade of change: HIV/AIDS, patients and access to medicines for all. Journal of International AIDS Society.

[17] Index Mundi (2020). Country Comparison: People living with HIV/ AIDS. Top 100 . Retrieved at https://www.indexmundi.com/g/r.aspx? $\mathrm{v}=35 \& \mathrm{t}=100$. Accessed 27/04/2020.

[18] Jennings, B. M., Heiner, S. I., Hemman, E., \& Swanson, K. M (2005). What really matter to health care consumers. J of Nur
Admin, 35 (4), 178-179.

[19] Joffe, S., Manocchia, M., Weeks, J. C. and Cleary, P. D. (2003). What do patients value in their hospital care? An empirical perspective on autonomy centred bioethics. $J$ of Med Ethics 29: 103-8.

[20] Kurth AE, Celum C, Baeten JM, Vermund SH, Wasserheit JN. Combination HIV prevention: significance, challenges, and opportunities. Curr HIV/AIDS Rep. 2011; 8 (1): 62-72.

[21] Kwesiga, D. (2010). A Comparative analysis of client satisfaction among people receiving HIV/AIDS care from public and private health facilities in Kabale District.

[22] Lamb, Jr. C. W., Hair, Jr. J. F., Mac Daniel, C., Boshoff, C. and Terblanche, N. S. (2004). Marketing. Second South African edition, Cape Town: Oxford University Press Southern Africa.

[23] Larson LN, Rovers JP, Mac Keigan LD. Patient satisfaction with pharmaceutical care: update of a validated instrument. J Am Pharm Assoc. 2002; 42: 44-50.

[24] Larsson, B. W., \& Larsson, G. (2009). Patients' views on quality of care and attitudes towards re-visiting providers. International Journal of Health Care Quality Assurance, 22 (6), 600-611.

[25] Lifson AR, Demissie W, Tadesse A, et al. HIV/AIDS stigmaassociated attitudes in a rural Ethiopian.

[26] Linder-Pelz, S. (1982). Social psychological determinants of patient satisfaction: a test of five hypotheses. So Sci Med; 16: 583-589.

[27] Linder-Pelz, S. (1982). Toward a theory of patient satisfaction. So Sci Med; 16: 577-582.

[28] Lochoro P. Measuring patient satisfaction in Uganda Catholic Medical Bureau Health Institutions. Health Policy and Development, 2004; 2 (3): 243-248.

[29] Lochoro, P 2004, 'Measuring patient satisfaction in ucmb health institutions'. Health Policy and Development, 2, 243248.000, An overview of customer satisfaction models. http://www.rpgroup.org.

[30] Lule, E., \& Haacker, M. (2012). The fiscal dimension of HIV/AIDS in Botswana, South Africa, Swaziland and Uganda The World Bank. Retrieved from http://www.avert.org: http://www.avert.org/hiv-aids-sub-saharanafrica.htm\#footnote $49 \mathrm{ydy} 85 \mathrm{ph}$.

[31] Magnusson, J., \& Sundin, E. (2005). Service Tangibility and Customer Loyalty: is there a relationship?

[32] May, S. J. (2001). Part 1: Patients satisfaction with management of back pain. Phy, 87 (1): 4-9.

[33] McDougall, G., \& Snetsinger, D. W. (1990). The intangibility of services: measurement and competitive perspectives. The journal of Services Marketing.

[34] Mehta, S. (2011). Service quality as predicator of patient satisfaction: A study of the healthcare sector. Journal of Health Management, 13 (2), 211-229.

[35] Metcalfe, C. J. and Klaber, and Moffett J. A. (2005). Do patients' expectations of physiotherapists affect treatment outcome? Part 2: Survey result. IntJnl of Therapy \& Rehab, 12 (3): 116-118. 
[36] Mohd, A., and Chakravarty, A., (2014). Patient satisfaction with services of the outpatient department. Med J Armed Forces India. 2014 Jul; 70 (3): 237-42. doi: 10.1016/j.mjafi.2013.06.010. Epub 2014 Jun 25. PMID: 25378776 ; PMCID: PMC4213903.

[37] Moser, C. A., and Kalton, G., (2017). Survey Method in social investigation. 2nd Edition. New York: Basic books, eBook ISBN: $9781315241999 . \quad$ Doi: https://doi.org/10.4324/9781315241999.

[38] NACA.(2015). End of Term Desk Review Report of the 20102015 National HIV/AIDS Strategic Plan.

[39] NACA. (2017). National Strategic Framework on HIV and AIDS: $2017-2021$.

[40] Nigeria National Agency for the Control of AIDS.(2014). Country Progress Report 2014.

[41] Okoye, U. O., Diekedie, A., \& Afemikhe, O. A. (2015). Perceived Barriers to Accessing and Adhering to Antiretroval Theraphy by People Living with HIV/AIDS (PLWHAs) in Akwa Ibom State, Nigeria. Research on Humanities and Social Sciences, 5.

[42] Omoseni O. Adepoju, Zacheus Opafunso and Modupe Ajayi (2017): Primary Healthcare in Southwest Nigeria: Evaluating service quality and patient's satisfaction, African Journal of Science, Technology, Innovation and Development, DOI: 10.1080/20421338.2017.1380585.

[43] Roser, M. (2018). Life Expectancy. Retrieved from ourworldindata.org: ourworldindata.org/life-expectancy.

[44] Saleh, J.-E. A., \& Adamu, H. I. (2015). Barriers to HIV/AIDS Treatment in NIgeria. American Journal of Health Research, 3 (5), 305-309.
[45] Sankar, P., Mora, S., Merz, J. F., and Jones, N. L., (2003). Patient perspectives of medical confidentiality: a review of the literature. J Gen Intern Med. 2003; 18: 659-669.

[46] Tran, B. X., Dang, A. K., Vu, G. T., Tran, T. T., Latkin, C. A., Ho, C. S. H., \& Ho, R. C. M., (2019). Patients satisfaction with HIV services in Vietnam: Status, Services models and associations with treatment outcomes. PloS one, 14 (11), [e0223723]. https://doi.org/10.137/journal.pone.0223723.

[47] UNAIDS (2010) Unite for universal access: Overview brochure on 2011 High Level Meeting on AIDS UNAIDS (2013). Gap Repor 2013. Geneva: UNAIDS.

[48] UNAIDS. (2013). The President's Comprehensive Reponse Plan.

[49] UNAIDS. (2014). Prevention Gap Report.

[50] UNAIDS. (2016). Prevention Gap Report.

[51] UNAIDS. (2016). The Gap Report.

[52] WHO Working Group. (2002). Draft: scaling up antiretroviral therapy in resource limited settings: guidelines for a public health approach. Geneva: W.H.O.

[53] WHO, W. H. (2006). Quality of Care; a process for making strategic choices in health systems.

[54] WHO, World Health Organization (2015). SDG 3: Ensure healthy lives and promote wellbeing for all at all ages. Retrieved from https://www.who.int/sdg/targets/en/2 Accessed on $10 / 04 / 2020$.

[55] Woodcock, A. and Bradley, C. 2001. Validation of the HIV treatment satisfaction questionnaire (HIVTSQ). Quality of Life Research 10 (6): 517-31. 